\title{
Quality of life in patients with dry age-related macular degeneration (dry AMD) treated with intravitreal bone marrow-derived stem cells (AMDCELL-clinical trial)
}

\author{
Rubens C Siqueira*, Carina C Cotrim, Luiza Toscano, Maristela D Orellana, André Messias and Rodrigo Jorge \\ Department of Ophthalmology, Otorhinolaryngology and Head and Neck Surgery, Ribeirao Preto School of Medicine, University of Sao Paulo, Sao Paulo, Brazil
}

\begin{abstract}
Background: Dry age-related macular degeneration (dry AMD) is a severe neurodegenerative disease of the retina that can lead to blindness. We assessed the visionrelated quality of life in patients with dry AMD treated with intravitreal bone marrow-derived stem cells.

Methods: The study included 10 patients with dry AMD treated with intravitreal bone marrow-derived stem cells. The vision-related quality of life was evaluated using the National Eye Institute Visual Function Questionnaire-25. Patients answered a questionnaire before treatment and 3 and 12 months after treatment.

Results: All patients completed the survey as scheduled. There was a statistically significant improvement $(p<0.05)$ in the quality of life of patients 6 months after treatment, especially in mental health $(p=0.003)$, colour vision $(p=0.005)$, general vision $(p=0.05)$, and dependence $(p=0.067)$. There was a decline in general health $(\mathrm{p}=0.77)$. There were improvements in the answers to other questions, but the results were not statistically significant.

Conclusion: Cell therapy with intravitreal bone marrow-derived stem cells improved the quality of life of patients with dry AMD. A larger number of cases will be necessary to more fully evaluate the effects of this therapy on the quality of life of these patients.
\end{abstract}

\section{Introduction}

Age-related macular degeneration (AMD) is a degenerative and disabling ocular disease that requires effective preventive and curative treatment [1]. Its main manifestation is progressive and irreversible loss of central vision in patients over 50 years of age [2-4]. It affects $8.7 \%$ of the elderly population worldwide [5] and has been predicted to affect approximately 196 million patients in 2020 and 288 million patients in 2040 [6]. It is the leading cause of blindness in patients over 50 years of age in developed countries [7]. In developing countries, such as Brazil, it is the third leading cause of blindness. However, because of changes in epidemiological profiles and because of the aging population, the severity is expected to increase.

The pathogenesis of AMD is not fully understood [8,9]. The two forms of AMD are exudative and dry AMD. Exudative AMD occurs less frequently (15\%) than dry AMD (85\%), with the former accounting for approximately two-thirds of significant visual losses $[3,10,11]$. Mechanisms for the development of geographic atrophy include ischemia, senescence, and oxidative and photo-oxidative damage and inflammation, either directly or through apoptotic mechanisms $[11,12]$.

While anti-vascular endothelial growth factor therapy has revolutionized the treatment of exudative AMD, the only currently approved treatment for dry AMD is based on the Age-Related Eye Disease Study (AREDS). This study reported that daily oral supplementation with antioxidant vitamins and minerals reduced the risk of developing advanced disease by $25 \%$ in five years $[8,9]$.

The treatment for dry AMD poses a challenge because there is no approved therapy. Based upon its pathology and limitations, studies have suggested therapeutic alternatives, including the use of stem cells
[13]. Some studies have evaluated the trophic effects on retinal diseases of autologous hematopoietic stem cells derived from the bone marrow [1,14-18]. In the current report, we used the National Eye Institute Visual Function Questionnaire (NEI-VFQ) to assess the quality of life status of patients with dry AMD treated with intravitreal use of bone marrow-derived stem cells.

\section{Methods}

The study protocol adhered to the tenets of the Declaration of Helsinki and was approved by the National Commission on Ethics in Research connected to the National Health Council of Brazil. The study was registered in clinicaltrial.gov (NCT01518127). It was conducted in a single centre (Hospital das Clinicas, Medical School Ribeirao Preto, Sao Paulo, Brazil). All participants gave written informed consent.

Patients were evaluated at the Retina and Vitreous Section of the Department of Ophthalmology, Otorhinolaryngology and Head and Neck Surgery, School of Medicine of Ribeirão Preto. Throughout the study, a single certified examiner performed the Early Treatment Diabetic Retinopathy Study best-corrected visual acuity (BCVA)

*Correspondence to: Rubens Camargo Siqueira, Department of Ophthalmology, Otorhinolaryngology and Head and Neck Surgery, Ribeirao Preto School of Medicine, University of Sao Paulo, Sao Paulo, Brazil, Tel: +55 (17) 32345858, Fax: +55 (17) 32140896; E-mail: rubenssiqueira@terra.com.br

Key words: age-related macular degeneration, dry AMD, stem cells, hematopoietic cells, quality of life

Received: February 18, 2019; Accepted: March 08, 2019; Published: March 12 2019 
measurement before any other study procedure. Ophthalmic evaluation was performed by a single retinal specialist (C.C.C.), and stereoscopic fundus photography, fluorescein and indocyanine green (ICG) angiography, microperimetry, and optical coherence tomography were performed by a single certified ophthalmic technician.

\section{Patient eligibility}

Patients were included if they had: 1) a diagnosis of hereditary retinal dystrophy classified clinically as dry AMD and 2) an Early Treatment Diabetic Retinopathy Study BCVA of 20/200 or worse. Exclusion criteria were: 1) a previous ocular surgery other than cataract extraction; 2) the presence of cataract or other media opacity that would prevent high-quality ocular imaging or that would affect the electroretinography or visual field evaluations; 3 ) the presence of other ophthalmic disease, such as glaucoma or uveitis; 4) a history of blood disorders, such as leukemia; 5) a known allergy to fluorescein or ICG angiography; or 6) known coagulation abnormalities or current use of an anticoagulative medication other than aspirin. If both eyes were eligible for treatment, the eye with the worse visual acuity (VA) was included in the study.

\section{Collection of the bone marrow aspirate}

The technique used to obtain a bone marrow aspirate was similar to the method used in oncological and haematological procedures for bone marrow transplantation. The procedure was performed in the Bone Marrow Transplantation Sector of the HCFMRP-USP by a team of haematologists. After antisepsis with iodopovidone and lidocaine anaesthesia, a needle was introduced into the posterior iliac crest, and 5-10 $\mathrm{mL}$ of bone marrow was aspirated using a syringe containing heparin.

\section{Cell processing}

The bone marrow aspirate was processed on the same day using Ficoll-Hypaque gradient centrifugation (Amersham Pharmacia, Piscataway, NJ, USA) to isolate mononuclear cells. The fraction containing mononuclear cells was resuspended in sterile saline and centrifuged again. The cells were characterized by flow cytometry using a panel of monoclonal antibodies to determine the presence and percentage of stem cells $\left(\mathrm{CD} 34^{+}\right)$and mature cells of hematopoietic and lymphoid origin. The average number of cells infused was $1.68 \times 10^{4}$ cells in a $0.1 \mathrm{~mL}$ suspension.

\section{Intravitreal injection}

All patients received a single $0.1 \mathrm{~mL}$ intravitreal injection of autologous bone marrow mononuclear fraction (BMMF) containing $\mathrm{CD} 34^{+}$cells in the eye with the worst visual acuity that was assessed using ophthalmic examinations. All intravitreal injections were performed by the same clinician. The technique followed established rules including preprocedural periocular and ocular preparation using topical polyvinylpyrrolidone with iodine (PVPI) and topical ophthalmic PVPI, respectively, and the establishment of a surgical field with a sterile blepharostat. A 30-gauge needle was used to perform an intravitreal injection in the upper temporal quadrant via pars plana at 4 and $3.5 \mathrm{~mm}$ from the limbus in phakic and pseudophakic eyes, respectively. After the procedure, antibiotic eye drops (a fourth-generation quinolone) were prescribed four times per day for seven days.

\section{Visual functioning questionnaire}

The NEI-VFQ was used to evaluate the patients' subjective visual functions (Siqueira 2011; Chew et al. 2013). The NEI-VFQ-25 provided an overall score as well as 12 subscale scores involving general health, general vision, near vision, distance vision, driving vision, peripheral vision, colour vision, ocular pain, vision-associated role limitations, dependency, social functioning, and mental health. The questionnaire emphasized vision difficulties in everyday life as well as vision-relevant psychosocial domains, such as mental health, social function, and role difficulties. The patients completed the questionnaires for demographic information and the NEI-VFQ, and their responses were checked at a scheduled visit by a psychologist when the patients were asked to complete any missing answers. The data from the questionnaire included sex, age, education, profession, and origin. All patients were instructed about the objectives and methodologies of the study, and all patients gave written informed consent to participate.

The questionnaire comprised five-point scale ratings that were transformed into percentages $(0-100 \%)$. Patients were scheduled to answer the questionnaire before treatment (baseline) and 3 and 6 months after treatment. After consultation with the Biostatistics Service, it was decided to obtain the outcome by descriptive statistical analyses. A value of $\mathrm{p} \leq 0.05$ was considered to be significant in all analyses.

\section{Results}

All patients completed the survey as scheduled. There was a statistically significant improvement $(\mathrm{p}<0.05)$ in the quality of life of patients six months after treatment, especially in issues related to mental health $(p=0.003)$, colour vision $(p=0.005)$, general vision $(p$ $=0.05)$, and dependence $(\mathrm{p}=0.067)$. There was a decline in general health $(p=0.77)$. There were improvements in the answers to the other questions that were not statistically significant (Figure 1).

The mean numbers of points of the pre-injection and 6-month questionnaires were 39 and 47, respectively. Analyses of the differences of the pre-injection and 6-month points showed that the patients with a lower visual acuity had a worse quality of life (lower score) with little improvement after the treatment. However, patients with a better visual acuity before treatment showed a significant improvement in the quality of life after the treatment (Figure 2).

In the same manner as the VA, the correlation between the mean sensitivity threshold at 6 months and the VFQ-25 difference showed that patients with less sensitive micrometry had lower scores and a lower quality of life 6 months after treatment, and patients with a better sensitivity in the pre-treatment microperimetry test had a significant improvement in the quality of life after treatment (Figure 3).

The hypo-autofluorescence area was also correlated with improvement of the VFQ-25 questionnaire after the injection, showing an inverse correlation between the hypo-autofluorescence area and an improvement in the quality of life score. Patients with a larger area of hyper-autofluorescence were those who had a significant improvement in the quality of life (Figure 4).

\section{Discussion}

Stem cells have great potential for treating degenerative diseases of the retina [15,18-20]. In the current study, 10 patients with dry AMD received a single intravitreal injection of a $0.1 \mathrm{~mL}$ suspension of BMMF containing $\mathrm{CD}_{3} 4^{+}$cells. Several studies have already reported that these cells derived from bone marrow are incorporated after intravitreal injections. Otani et al. was one of the first to demonstrate the presence of hematopoietic stem cells up to 6 months after intravitreal injections in mice [21]. Caballero et al. [22] also reported that bone marrow CD34 cells had the capacity to engraft in the damaged retina and its vasculature after intravitreal injections. 


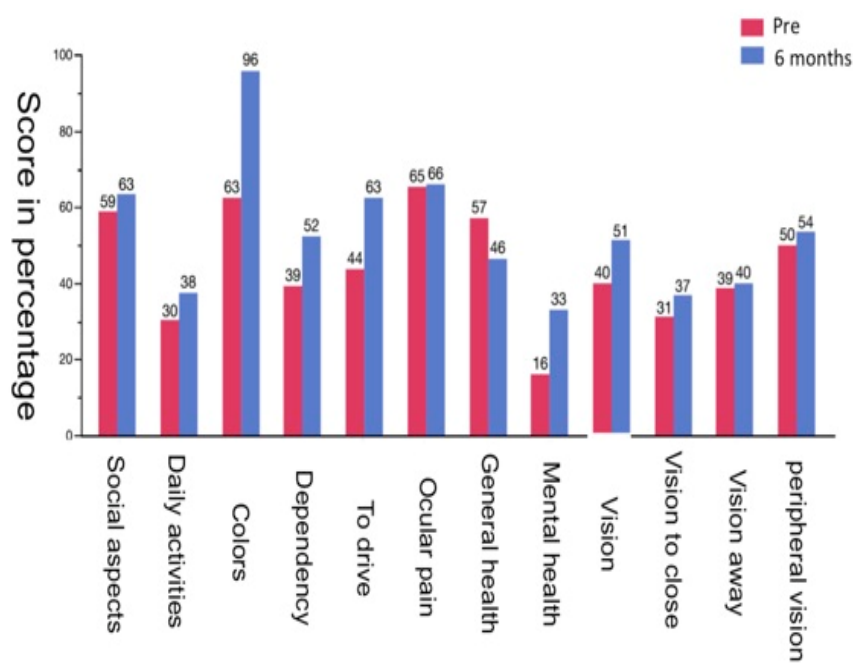

Figure 1. The 12 subdomains analyzed by the Visual Function Questionnaire-25 and a comparison of pre-injection results and the results 6 months after treatment.

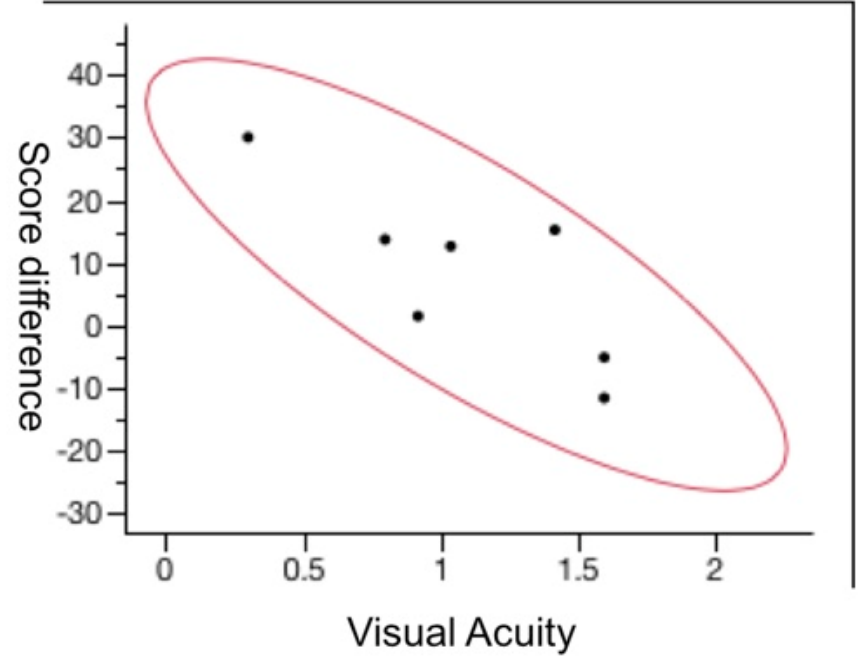

Figure 2. The correlation of visual acuity at 6 months with the difference in points on the Visual Function Questionnaire-25 (p=0.03)

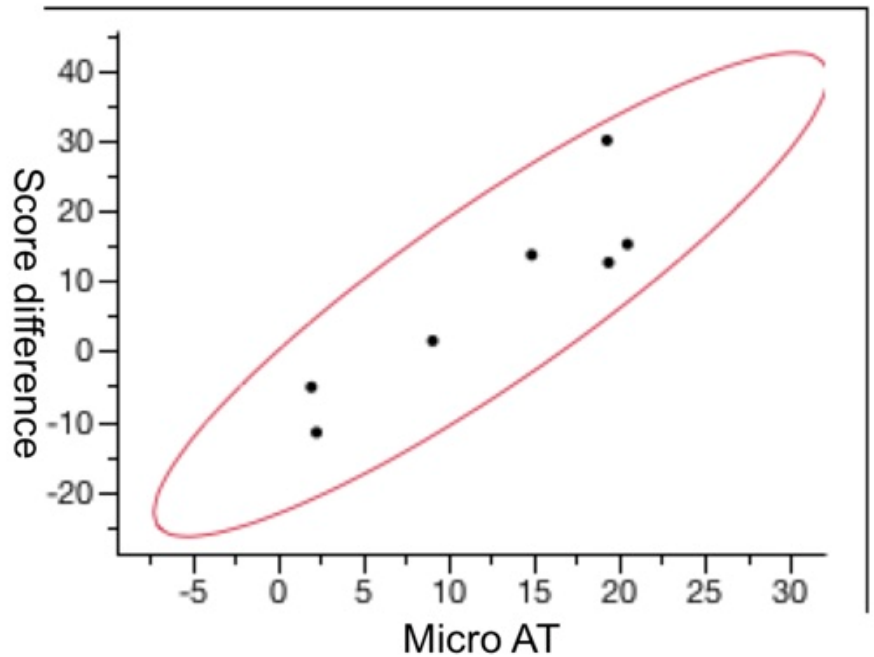

Figure 3. The mean correlation of the microperimetry average threshold (micro AT) at 6 months with the difference in points on the Visual Function Questionnaire-25 at 6 months after treatment $(\mathrm{p}=0.005)$ 
Siqueira RC (2019) Quality of life in patients with dry age-related macular degeneration (dry AMD) treated with intravitreal bone marrow-derived stem cells (AMDCELL-clinical trial)

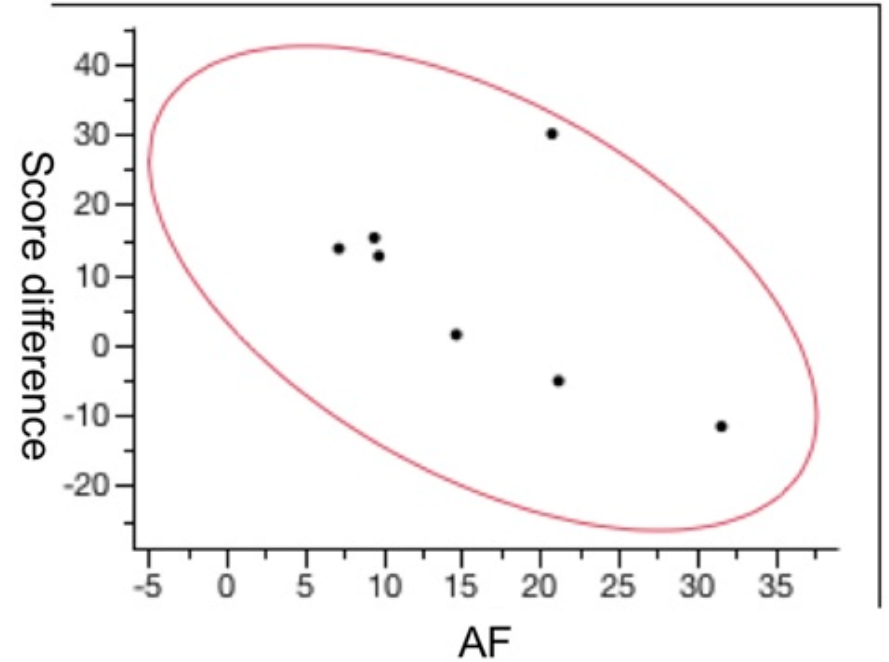

Figure 4. The correlation between the size of the hypo-fluorescence area and the poin difference on the Visual Function Questionnaire-25 questionnaire at 6 months after treatment $(\mathrm{p}=0.005)$

In the current study, we determined the quality of life using the VFQ-25 questionnaire. Siqueira et al. have already performed this analysis in 20 patients with retinitis pigmentosa who received intravitreal autologous BMMF containing $\mathrm{CD} 34^{+}$cells. There was a significant improvement in the quality of life after 3 months of followup. The authors also observed that the quality of life was directly related to macular sensitivity (Siqueira et al. 2015a).

The results of the current study showed improvements in the quality of life at 6 months, especially in mental health and colour vision. Mental health was evaluated using four questions about concerns because of a lack of vision, fear of making mistakes when performing activities that were already routine, and embarrassing confusion about bathroom and toilet activities. Based on the 6-month questionnaire after treatment, the patients were more confident performing these activities. These results were important because the mental health question had the lowest score (16\%) among the 12 questions evaluated before the therapy. For example, the answer to the mental health question was worse than the question concerning near vision (31\%). Colour vision was analysed by a question concerning the difficulty of patients to choose and combine clothes by themselves. Although many patients no longer had this difficulty, there was a significant improvement at 6 months after treatment. As in a previous study by Siqueira et al., there was a correlation of the best sensitivity in microperimetry with a significant improvement in the quality of life at 6 months. There was also a significant and directly proportional correlation between patients with a higher quality of life and a better VA that was inversely proportional to the size of the hypo-autofluorescence lesion obtained from autofluorescence retinography.

\section{Conclusion}

Cell therapy using intravitreal injection of bone marrow-derived stem cells improved the quality of life of patients with dry AMD. In future studies, a larger number of cases and longer follow-up will be necessary to further evaluate the effects of this therapy on the quality of life of patients.

\section{Acknowledgements}

We thank the cell therapy centre of the hemocenter at the University of São Paulo/ Ribeirão Preto.

\section{References}

1. Centurion V, Lacava AC, Caballero JC (2004) Intraocular Lens with yellow chromophore results. Rev Bras Oftalmol 63: 424-431.

2. Fritsche LG, Fariss RN, Stambolian D, Abecasis GR, Curcio CA et al. (2014) Agerelated macular degeneration: genetics and biology coming together. Annu Rev Genomics Hum Genet 15: 151-171. [Crossref]

3. Khan M, Agarwal K, Loutfi M, Kamal A (2014) Present and possible therapies for agerelated macular degeneration. ISRN Ophthalmol 2014: 608390. [Crossref]

4. Mavija M, Alimanovic E, Jaksic V, Kasumovic SS, Cekic S, et al. (2014) Therapeutic modalities of exudative age-related macular degeneration. Med Arch 68: 204-208. [Crossref]

5. Cascella R, Ragazzo M, Strafella C, Missiroli F, Borgiani P, et al. (2014) Age-related macular degeneration: insights into inflammatory genes. J Ophthalmol: 582842. [Crossref]

6. Wong WL, Su X, Li X, Cheung CM, Klein R, et al. (2014) Global prevalence of age-related macular degeneration and disease burden projection for 2020 and 2040 a systematic review and meta-analysis. Lancet Glob Health 2: e106-e116. [Crossref]

7. Friedman DS, O'Colmain BJ, Muñoz B, Tomany SC, McCarty C, et al. (2004) Prevalence of age-related macular degeneration in the United States. Arch Ophthalmol 122: 564-572. [Crossref]

8. Age-Related Eye Disease Study 2 Research Group (2013) Lutein + zeaxanthin and omega-3 fatty acids for age-related macular degeneration: The Age-Related Eye Disease Study 2 (AREDS2) randomized clinical trial. JAMA 309: 2005-2015.

9. Age-Related Eye Disease Study 2 (AREDS2) Research Group1, Chew EY, SanGiovanni JP, Ferris FL, Wong WT, et al. (2013) Lutein/zeaxanthin for the treatment of age-related cataract: AREDS2 randomized trial report no. 4. JAMA Ophthalmol 131 843-850. [Crossref]

10. Siqueira RC (2011) Stem cell therapy for retinal diseases: update. Stem Cell Res Ther 2: 50. [Crossref]

11. Siqueira RC, Messias A, Voltarelli JC, Scott IU, Jorge R (2011) Intravitreal injection of autologous bone marrow-derived mononuclear cells for hereditary retinal dystrophy: a phase I trial. Retina 31: 1207-1214. [Crossref]

12. Schwartz SD, Hubschman JP, Heilwell G, Franco-Cardenas V, Pan CK, et al. (2012) Embryonic stem cell trials for macular degeneration: a preliminary report. Lancet 379 : 713-720. [Crossref]

13. Taskintuna I, Elsayed MEAA, Schatz P (2016) Update on clinical trials in dry agerelated macular degeneration. Middle East Afr J Ophthalmol 23: 13-26. [Crossref]

14. Siqueira RC, Voltarelli JC, Messias AM, Jorge R (2010) Possible mechanisms of retinal function recovery with the use of cell therapy with bone marrow-derived stem cells. Arq Bras Oftalmol 73: 474-479. [Crossref]

15. Park SS, Caballero S, Bauer G, Shibata S, Roth A, et al. (2012) Long-term effects of intravitreal injection of GMP-grade bone-marrow-derived CD34(+) cells in NODSCID mice with acute ischemia-reperfusion injury. Invest Ophthalmol Vis Sci 53: 986994. [Crossref]

16. Siqueira RC, Messias A, Messias K, Arcieri RS, Ruiz MA, et al. (2015a) Quality of life in patients with retinitis pigmentosa submitted to intravitreal use of bone marrowderived stem cells (Reticell -clinical trial). Stem Cell Res Ther 6: 29.

17. Siqueira RC, Messias A, Gurgel VP, Simoes BP, Scott IU et al. (2015b) Improvement of ischaemic macular oedema after intravitreal injection of autologous bone marrowderived haematopoietic stem cells. Acta Ophthalmol 93: e174-e176. [Crossref]

18. Park SS, Moisseiev E, Bauer G, Anderson JD, Grant MB, et al. (2017) Advances in bone marrow stem cell therapy for retinal dysfunction. Prog Retin Eye Res 56: 148165. [Crossref]

19. Pellegrini G, De Luca M, Arsenijevic Y (2007) Towards therapeutic application of ocular stem cells. Semin Cell Dev Biol 18: 805-818. [Crossref]

20. Tibbetts MD, Samuel MA, Chang TS, Ho AC (2012) Stem cell therapy for retinal disease. Curr Opin Ophthalmol 23: 226-234. [Crossref]

21. Otani A, Dorrell MI, Kinder K, Moreno SK, Nusinowitz S, et al. (2004) Rescue of retinal degeneration by intravitreally injected adult bone marrow-derived lineagenegative hematopoietic stem cells. J Clin Invest 114: 765-774. [Crossref]

22. Caballero S, Sengupta N, Afzal A, Chang KH, Calzi SL, et al. (2007) Ischemic vascular damage can be repaired by healthy, but not diabetic, endothelial progenitor cells. Diabetes 56: 960-967. [Crossref]

Copyright: (C2019 Siqueira RC. This is an open-access article distributed under the terms of the Creative Commons Attribution License, which permits unrestricted use, distribution, and reproduction in any medium, provided the original author and source are credited. 